
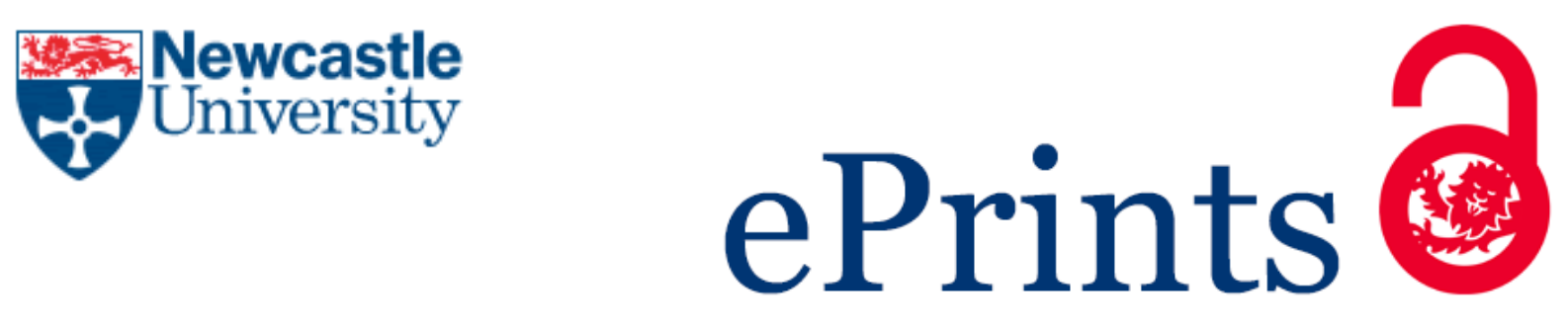

Choong Z, O'Neil A, Degenaar P, Huo D. Effect of crystallographic orientation and employment of different cutting tools on micro-end-milling of monocrystalline silicon. Proceedings of the Institution of Mechanical Engineering, Part B: Journal of Engineering Manufacture 2016. DOI: 10.1177/0954405415612379

Copyright:

(C) The authors, 2015.

DoI link to article:

http://dx.doi.org/10.1177/0954405415612379

Date deposited:

$01 / 02 / 2016$

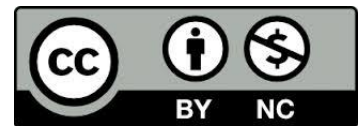

This work is licensed under a Creative Commons Attribution-NonCommercial 3.0 Unported License 


\title{
EFFECT OF CRYSTALLOGRAPHIC ORIENTATION AND EMPLOYMENT OF DIFFERENT CUTTING TOOLS ON MICRO-END- MILLING OF MONOCRYSTALLINE SILICON
}

\section{Zi Jie Choong ${ }^{1}$, Dehong Huo ${ }^{*}$, Patrick Degenaar $^{2}$, Anthony O'Neill ${ }^{2}$}

1 School of Mechanical and Systems Engineering, Newcastle University, Newcastle Upon Tyne, NE1 7RU, UK

2 School of Electrical and Electronic Engineering, Newcastle University, Newcastle Upon Tyne, NE1 7RU, UK

*Corresponding author: Tel: +44 191208 6230, email: dehong.huo@ newcastle.ac.uk

\begin{abstract}
This paper presents the research on the effect of crystallographic orientation and different cutting tool effect during micro-milling of (001) silicon wafer. Excessive generation of undesirable surface and subsurface damages often occurs when machined at thick depth of cut of several hundreds of microns. Up-milling operations along $\langle 100\rangle$ and $\langle 110\rangle$ directions were performed on a (001) wafer and the results shows that machining surfaces along $<100>$ were of better quality than those of $\langle 110\rangle$ and is in agreement with previous studies. In addition, comparative studies of diamond coated, CVD and single crystal diamond end-mills were performed along [0 $\overline{1} 0]$ at $150 \mu \mathrm{m}$ deep. Results shows that diamond coated tool generates the least edge chipping amongst the three. This might be due to the large negative rake angle creating highly compressive hydrostatic pressure in the cutting zone and therefore suppressing the crack propagation. Furthermore, no visible defects were detected on the bottom machined surface when machined by CVD and single crystal diamond end-mills. Surface edge chipping however remains a challenge even though micro-milling were performed along $\langle 100\rangle$ with single crystal diamond end-mill. Apart of milling along <100>, protection to the top silicon surface are required to achieve fracture free quality micro-milled silicon.
\end{abstract}


Keywords: Micro-End-Milling, Monocrystalline Silicon, Crystallographic Orientation, Diamond End-Mills.

\section{INTRODUCTION}

Hard brittle materials such as silicon, silicon carbide and gallium nitride are ubiquitously used in the semiconductor and Micro-Electro-Mechanical Systems (MEMS) industrial sectors. Fabrication of these materials micro-scale level can be challenging when stringent specifications such as a good surface finish and high accuracy form factor are required. Additive techniques are not generally applicable for crystalline materials due to the difficulty of patterning the growth of good quality material. As such, subtractive techniques such as deep reactive ion etching (DRIE) and either isotropic or anisotropic Wet Etching were typically used in the MEMS/semiconductor industries. These techniques can achieve patterned subtraction by patterning etch stops via photolithography. These techniques lend themselves well to large scale manufacture, but require lithographic processing and are largely limited to flat surfaces. ${ }^{1,2}$

Furthermore, laser based lithographic techniques have been shown to achieve good quality finishing. However it requires picoseconds lasing which is very slow and is less suitable for processing of transparent materials such as Gallium Nitride. Alternatively, silicon is also manufactured mechanically by grinding, lapping and polishing. Thus, mechanical micro-milling is a potential maskless alternative that could achieve new types of non-planar, potentially three-dimensional structures. Machining of crystalline materials with ductile mode cutting to achieve good surface integrity had been studied with different approaches using ultra-precision micromachining. ${ }^{3,4,5,6}$ In addition, Huo et al. had also systematically characterized the surface and subsurface in micro milling of monocrystalline silicon. ${ }^{7}$

Despite micro-milling showing potential in micromachining of ductile materials such as aluminum, excessive generation of surface and subsurface damages remains a challenge in 
silicon micro-milling. This often occurs when silicon is machined at hundreds of microns in depth. Due to a lack in studies on the effect of crystallographic orientation and behaviour of different cutting tools on silicon micro-milling, this paper aims to provide fundamental understandings on the anisotropic behaviour and the effect of different cutting tools on silicon during micro-milling.

\subsection{Representation of Silicon Crystallographic Orientation using Miller Index}

Silicon has a cubic crystalline structure in which its crystal lattice can be explained using a simple cube. Miller index, denoted by three integers $h k l$ which corresponds to the respective $\mathrm{XYZ}$ axes are used to represent the designated planes and directions with respect to the principal axes. ${ }^{2}$ Specific direction and planes are represented by square and round brackets respective. In the case of an opposite direction or plane, a bar is used to denote the opposite of a specific direction or plane rather than a minus sign. ${ }^{8}$

Furthermore, the integers which denotes a specific plane is similar to the specific direction perpendicular to that plane. For example, the (100) plane represents the plane on the $\mathrm{X}$ axis. The direction of $\mathrm{X}$ axis represented by [100], is perpendicular to the $\mathrm{X}$ axis plane. Figure 1 shows the cubic structure of silicon crystal with its principal axes denoted using Miller Indices. In addition, Table 1 also shows the definitions of each representation to the descriptor of either direction or plane.

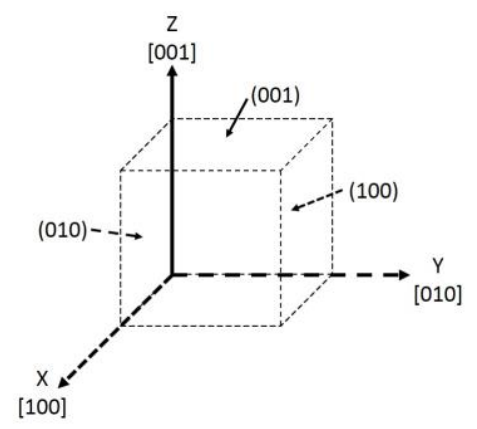

Figure 1: Miller Index representation on a cubic system.

Table 1: Definitions of Miller Index notation for plane and direction. 


\begin{tabular}{cc}
\hline Denotations & Definitions \\
\hline\{\} & Family of planes. E.g. $\{100\}=(100),(010),(001)$ and reciprocals. \\
() & A specific plane. \\
$<>$ & Family of directions. E.g. $<100>=[100],[010],[001]$ and reciprocals. \\
{[]} & A specific direction. \\
\hline
\end{tabular}

\subsection{Anisotropy Properties of Silicon}

Location of the primary flat of a (001) silicon wafer is aligned with the [110] direction with its natural cleavage plane usually runs along $\langle 110\rangle$ and $\langle 111\rangle{ }^{8}$ Fracture on a silicon is orientation-dependence due to the different bonding forces between each atoms at different directions within the silicon lattice. Mechanical properties such as the Young's modulus and fracture toughness were also studied to explain the anisotropic fracture behaviour of silicon during machining. Young's modulus of the silicon can be calculated using Equation (1): ${ }^{9}$

$$
\frac{1}{\mathrm{E}_{h k l}}=\mathrm{S}_{11}-2\left[\left(\mathrm{~S}_{11}-\mathrm{S}_{12}\right)-\frac{1}{2} \mathrm{~S}_{44}\right]\left(\mathrm{m}^{2} \mathrm{n}^{2}+\mathrm{n}^{2} \mathrm{p}+\mathrm{m}^{2} \mathrm{p}^{2}\right)
$$

Where:

- E is the Young's modulus

- $h k l$ is the three-integer triples corresponding to $\mathrm{XYZ}$ axis in a coordinate system.

- $\quad m, n$ and $p$ are the cosine of angles between direction of interest denoted by $[h k l]$

- $\mathrm{S}_{i j}$ is the compliance constant $\left(\mathrm{S}_{11}=7.68 ; \mathrm{S}_{12}=-2.14 ; \mathrm{S}_{44}=12.6\right)$

According to Equation (1), Young's modulus is similar on all crystallographic directions for a (111) wafer plane at $188 \mathrm{GPa}$. However the Young's modulus on a (001) wafer plane exhibits a fourfold symmetry behaviour at $169 \mathrm{GPa}$ and $130 \mathrm{GPa}$ along the <110> and <100> directions respectively. Fracture toughness of silicon, which determines its resistance against crack propagation, is also highly orientation-dependence. Using Griffith criterion, fracture toughness at each crystallographic directions can be computed using Equation (2): ${ }^{10}$

$$
\mathrm{K}_{\mathrm{IC}}=\sqrt{\frac{2 \gamma_{h k l} E_{h k l}}{\left(1-\mathrm{v}^{2}\right)}}
$$


Where:

- $\quad \gamma_{h k l}$ is the surface energy of any $h k l$ directions.

Values of the fracture toughness reported by several articles for $\{100\},\{110\}$ and $\{111\}$ wafers are shown in Table 2. According to the behaviour of these fracture toughness as shown in Table 2 , it can be recognized that $\langle 100\rangle$ directions has the highest resistance against crack propagations when compared to $\langle 110\rangle$ and $\langle 111\rangle$.

Table 2: Silicon's fracture toughness values from literatures.

\begin{tabular}{cccc}
\hline & \multicolumn{3}{c}{ Fracture Toughness $\left(\mathbf{M P a . m}^{\mathbf{1 / 2}}\right)$} \\
\cline { 2 - 4 } Fracture Planes & $\mathbf{1 1 0 0}\}$ & $\mathbf{1 1 0 \}}$ & $\{\mathbf{1 1 1}\}$ \\
\hline (Jaccodine et al.) $^{11}$ & 0.75 & 0.71 & 0.62 \\
(Chen et al.) $^{12}$ & 0.95 & 0.90 & 0.82 \\
(Hayashi et al.) $^{13}$ & $1.14-1.19$ & $1.07-1.18$ & $0.82-1.15$ \\
(Tanaka et al.) $^{14}$ & 0.89 & 0.73 & 0.68 \\
\hline
\end{tabular}

\subsection{Review on the Effect of Crystallographic Orientation on Silicon Micromachining}

During the early discovery of surface anisotropy on silicon mechanical micromachining, Blackley et al. shows that the damages caused by orientation-dependent was contributed by the variation of resolved tensile stress in the $\{111\}$ slip planes. ${ }^{2}$ In addition, relative changes between the machined orientation plane and cutting direction during micro-turning of silicon was also consider in the recent years to explain the machining quality of orientationdependent silicon surface.

Shibata et al. performed nanoscale ductile mode micro-turning on silicon with crystal surface of (001) and (111). ${ }^{15}$ A slip model was used in the qualitative analysis to explain the machined surface effect when turned at different directions. The experiment also shows the anisotropic effect of machined surface taking the form of a fourfold and threefold symmetric across the center of (001) and (111) wafer respectively. Hung et al. studied the effect of crystallographic orientation during ductile mode turning of (100) silicon wafer. ${ }^{16}$ The study shows that micro pitting occurs along $\langle 100\rangle$ while ductile mode was achieved along $\langle 110\rangle$. 
Cheung had also performed ductile mode micro-turning on (001) and (110) wafers. $^{17}$ Surface roughness measured across each crystallographic directions indicates a variation in roughness value when the relative machined surface plane and the cutting directions changes during turning. O'Connor et al. shows the measurement of critical chip thickness as a function of crystallographic orientation under different cutting conditions and directions on a (001) wafer. ${ }^{18}$ Results from the experiments indicates that cutting force measured from dynamometer varies when turned at different directions and ductile mode cutting on (001) wafer can be achieved at a maximum depth of cut of $120 \mathrm{~nm}$ in [100] and $40 \mathrm{~nm}$ in [110] respectively. Jasinevicius et al. had also showed that the critical chip thickness in ductile material removal mode for (100) silicon wafer reaches a maximum of $285 \mathrm{~nm}$ in [100] and $110 \mathrm{~nm}$ in [110] respectively. ${ }^{19}$ Cracks were also found to be easily formed along <110> when micro-turned at sub-micrometer depth of cut.

\subsection{Review on the Effects of Different Cutting Tools on Silicon Micro-Milling}

Coated Tungsten carbide (WC) and single crystal diamond tools are commonly used for micromachining of silicon. Rusnaldy et al. had performed a comparative study on micromilling with TiCN, TiAin and diamond coated tungsten carbide tools on a (111) silicon wafer. ${ }^{20}$ Experiments were conducted in terms of ductile regime machining with an axial depth of cut at 0.3 and $0.5 \mu \mathrm{m}$. Results from the investigation shows that micro-milling performed with diamond coated tungsten carbide tool produces the least amount of fracture along the machined surface with a surface roughness measured at $60.7 \mu \mathrm{m}$.

Although coating helps to increase resistance against wear and resistance, the thickness of the coatings would increase in cutting edge radius and therefore causing the cutting tool to be blunt. Due to the size effect in microstructure affecting the machining quality of the work piece, coating on micro-cutting tools might have a negative effect to the micromachining performance. Chemical vapour deposited and single crystal diamond tools possessing 
exceptional hardness have been introduced for micromachining during the recent years. ${ }^{21}$ As the cutting edge radius is in sub-micrometer, the tool cutting edge is considered to be very sharp for micro-cutting processes. 


\section{EXPERIMENTAL METHODOLOGY}

\subsection{Methods for Effect of Crystallographic Orientation on Silicon Micro-Milling}

\subsubsection{Workpiece and Machining Equipment Setup}

A 15 x $15 \mathrm{~mm}$ work-piece was cleaved from a (001) silicon with 500um and $100 \mathrm{~mm}$ in thickness and diameter respectively as shown in Figure 2. Micro-milling operations was conducted along $\langle 100\rangle$ and $\langle 110\rangle$ on the (001) surface. Each cutting direction was varied at $45^{\circ}$ between $0^{\circ}$ and $360^{\circ}$ and the machining conditions were shown in Table 3.

The sample was bonded onto a ground metal plate and clamped onto a work-piece holder. Experiment was conducted on Nanowave MTS5R micro-milling system as shown in Figure

3. It consists of a three-axis motion stage, whereby the $\mathrm{Y}$ axis actuates the high speed air bearing spindle with a $0.5 \mathrm{~mm}$ diameter UT coated tungsten carbide end mill by Air Bearings Ltd and Union Tool Co. respectively. Furthermore, the $\mathrm{X}$ and $\mathrm{Z}$ axes actuate the work-piece holder and Kistler dynamometer for cutting force measurement during machining.

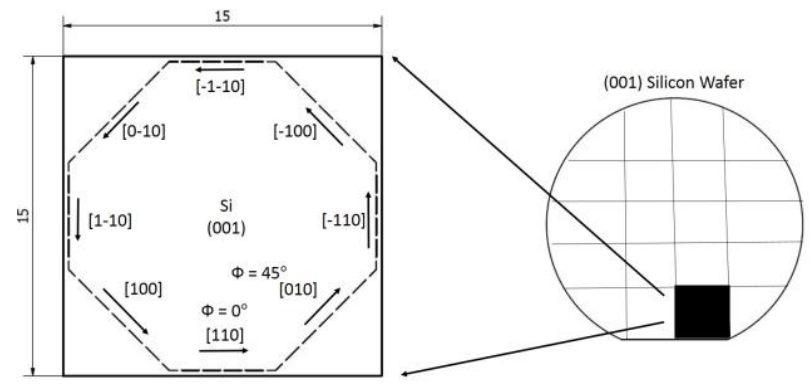

Figure 2: Illustration of silicon work-piece and machining schematic.

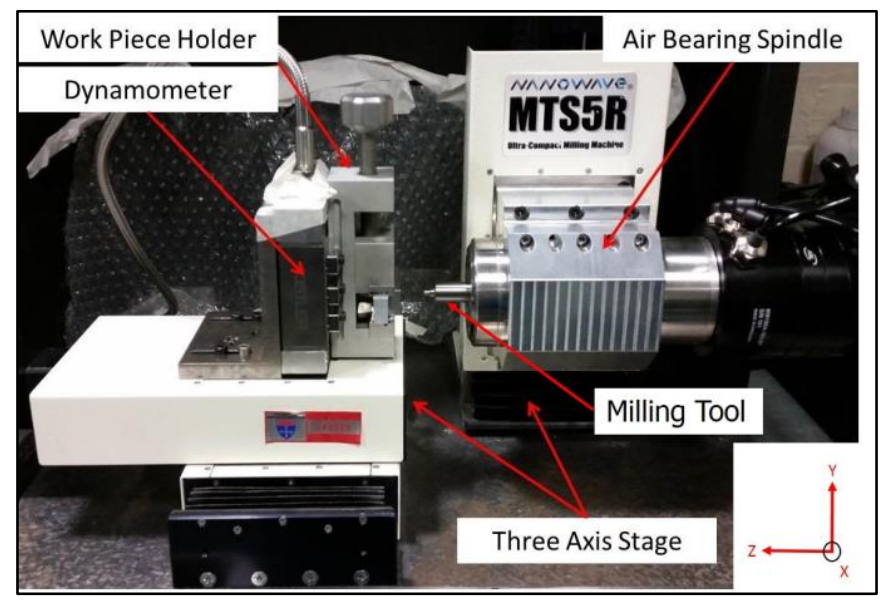

Figure 3: Nanowave MTS5R micro-milling system for performing milling along $\langle 100\rangle$ and $\langle 110\rangle$ directions on a $(001)$ silicon wafer. 
Table 3: Machining conditions for micro-milling operations on a (001) silicon wafer.

\begin{tabular}{cc}
\hline Cutting Conditions & Parameters \\
\hline Spindle Speed (rpm) & 40,000 \\
Cutting Speed $(\mathrm{m} / \mathrm{min})$ & 62.83 \\
Feed Per Tooth $(\mu \mathrm{m} /$ tooth $)$ & 0.15 \\
Depth of Cut $(\mu \mathrm{m})$ & 10 \\
\hline
\end{tabular}

\subsubsection{Cutting Strategy - Up Milling}

Micro-milling mechanics includes two cutting operations namely slot and side milling. Furthermore, there are two strategies within side milling comprising of either up or down milling. ${ }^{22}$ Chip formation in ductile mode occurs when the uncut chip thickness is sufficiently small with the ratio of tool cutting edge radius to uncut chip thickness $>1$.

In an up-milling process as shown in Figure 4, the uncut chip thickness begins from a minimum value at the start of cut and approaches a higher value when the cutting tool rotates. This allows minimal material removal at the start of each cut while its critical chip thickness will only be reached at the later stage. Due to the cutter rotating almost instantaneously along the respective cutting directions, the final machined surface is therefore formed by the exposed surfaces from removed materials in the ductile region during multiple cutting passes. As silicon is brittle, up-milling was applied to ensure minimal damages will be incurred on the final machined surfaces which is aligned with the cutter's feed direction.

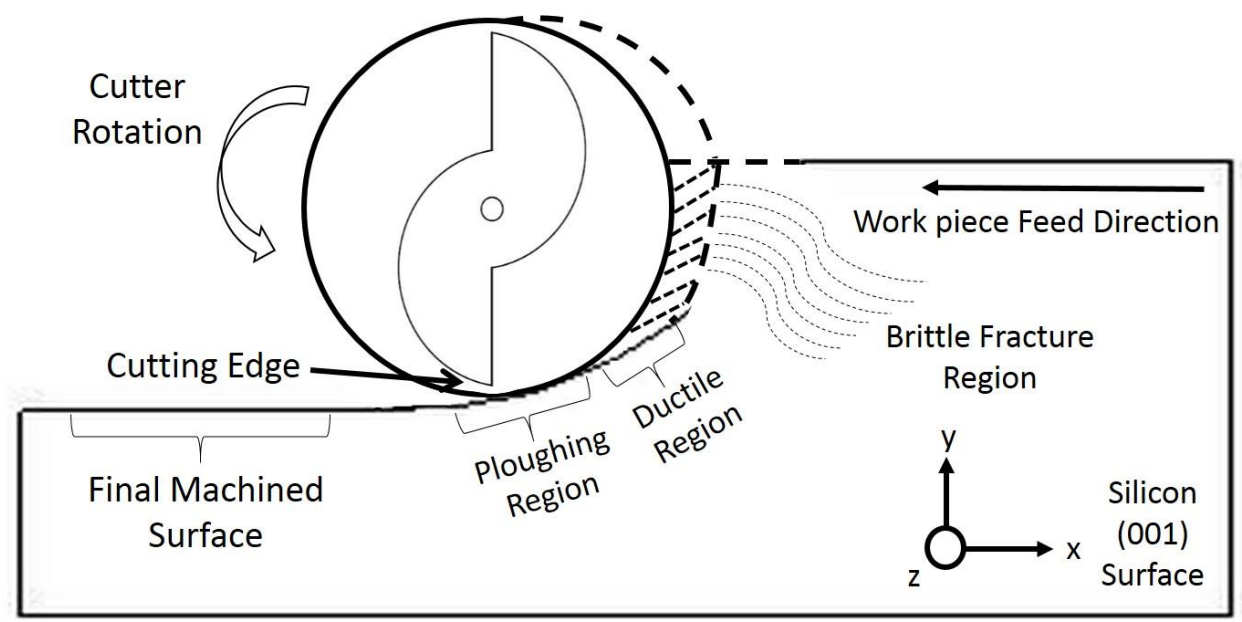

Figure 4: Schematic of up-milling process where the chip thickness begins at minimal and increases towards the end of each cut. 


\subsection{Effect of Different Cutting Tools on Silicon Micro-Milling}

Comparative studies on the effect of different cutting tools on silicon micro-milling were conducted using three different end mills namely diamond coated tungsten carbide tool, chemical vapour deposited (CVD) diamond tool and single crystal diamond tool. Diameter of each cutting tool were similar at $\Phi 0.5 \mathrm{~mm}$. Figure 5 shows a schematic of the machining plan on the (001) wafer. Table 4 also shows the parameters and profile specifications for machining of each wafer and the conditions were kept constant throughout each milling operations.

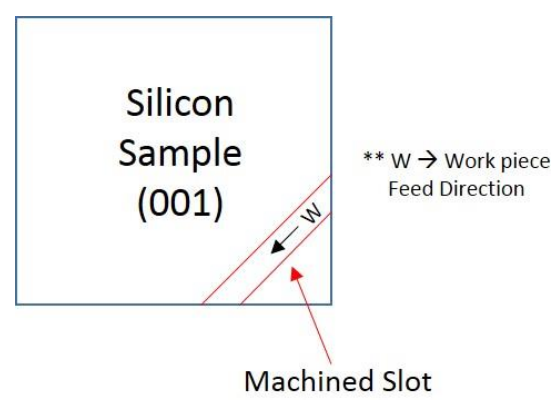

Figure 5: Schematic of machining plan for investigation on the effect of different cutting tools on silicon micro-milling.

Table 4: Machining conditions for comparative studies on different cutting tools.

\begin{tabular}{cc}
\hline \multicolumn{1}{c}{ Machining Parameters } \\
\hline Cutting Conditions & Parameters \\
Spindle Speed $(\mathrm{rpm})$ & 40,000 \\
Cutting Speed $(\mathrm{m} / \mathrm{min})$ & 62.83 \\
Feed Per Tooth for Diamond Coated Tungsten Carbide Tool $(\mu \mathrm{m} /$ tooth $)$ & 0.075 \\
Feed Per Tooth for CVD and Single Crystal Diamond Tool $(\mu \mathrm{m} /$ tooth $)$ & 0.15 \\
Axial Depth of Cut $(\mu \mathrm{m})$ & 10 \\
Width of Cut $(\mu \mathrm{m})$ & 500 \\
\hline Machine Profile Specifications & 150 \\
\hline Total Depth of Cut $(\mu \mathrm{m})$ & 6 \\
Slot Length $(\mathrm{mm})$ & {$[0 \overline{1} 0]$} \\
\hline Cutting Directions &
\end{tabular}




\section{RESULTS AND DISCUSSION}

Quantitative and qualitative analysis were conducted on the cutting performance of silicon after micro-milling operations. A distinct crystallographic orientation dependence behaviour was observed. In this section, metrology techniques and the experimental results will be discussed

\subsection{Effect of Crystallographic Orientation during Silicon Micro-Milling}

\subsubsection{Cutting Force Analysis}

Drift compensation was performed by zeroing all the measured data prior to signal processing. Raw cutting force data were then processed with a $2^{\text {nd }}$ order low pass filter to remove any high frequency noises. Ten cycles of cutting force at each cutting directions were obtained for analysis. Finally, the average resultant cutting force at each direction was computed by Equation (3):

$$
\text { Average Resultant Cutting Force }=\frac{\sqrt{F_{x}{ }^{2}+F_{y}{ }^{2}+F_{z}{ }^{2}}}{\mathrm{n}}
$$

Where:

- $F_{x}, F_{y}$ and $F_{z}$ are the processed cutting force at each time point at a specific cutting direction $[h k l]$.

- $\mathrm{n}$ is the total time point at a specific cutting direction $[h k l]$.

Figure 6 shows the average resultant cutting force of the eight directions as illustrated in Figure 2. Cutting forces measured along $<100\rangle$ directions were significantly larger than those of $\langle 110\rangle$, thus suggesting a greater ductility characteristics along $\langle 100\rangle$. Such phenomenal were expected due to a lower force required to cut the cleavage plane along <110> directions. A fourfold behaviour similar to the silicon cubic crystal structure, repeats at every $90^{\circ}$. 


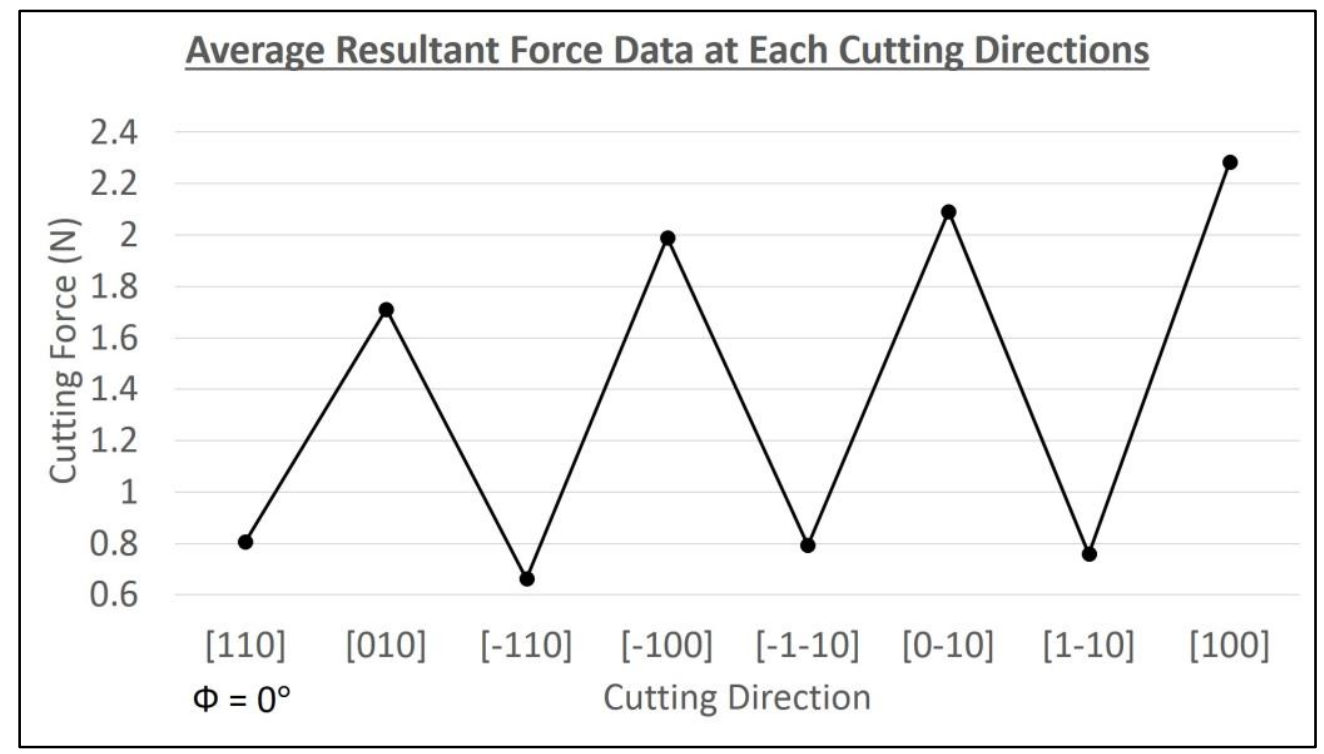

Figure 6: Results of average resultant cutting force at the respective cutting directions.

\subsubsection{Analysis on Surface Roughness and Edge Chipping}

Hitachi TM3030 SEM system and Zygo NewView 5020 optical surface profiler with 10x objective were used for both edge chipping and surface roughness analysis. Edge chipping was quantitatively characterized by measuring the length of edge chipping illustrated by the schematic shown in Figure 7. Assessment was performed in the middle region of each machined surface along [010] and [110] directions. Average measurement of the length of edge chipping was obtained from fifty equally spaced data points along an approximate length of $220 \mu \mathrm{m}$. Figure 8 and Table 5 shows the SEM images and quantitative measurements of the respective machined surfaces.

Results from both surface roughness and edge chipping measurement shown in Table 5 were in agreement with the orientation-dependent crack propagation behaviour of silicon. Relationship between fracture toughness of $\langle 110\rangle$ and $\langle 100\rangle$ shown in Table 2 suggests that $\mathrm{K}_{\mathrm{IC}<100>}>\mathrm{K}_{\mathrm{IC}<110>}$. In addition, possible contribution of vibration from the cutting tool causes higher cutting forces to be measured along $\langle 100\rangle$ directions. Vibration causes periodic variation in the actual depth of cut which leads to large ploughing effect on the cutting edge of work-piece and high frictional force. This leads to minor edge chipping and partial ductile quality on the bottom surface as shown in Figure 8a. 


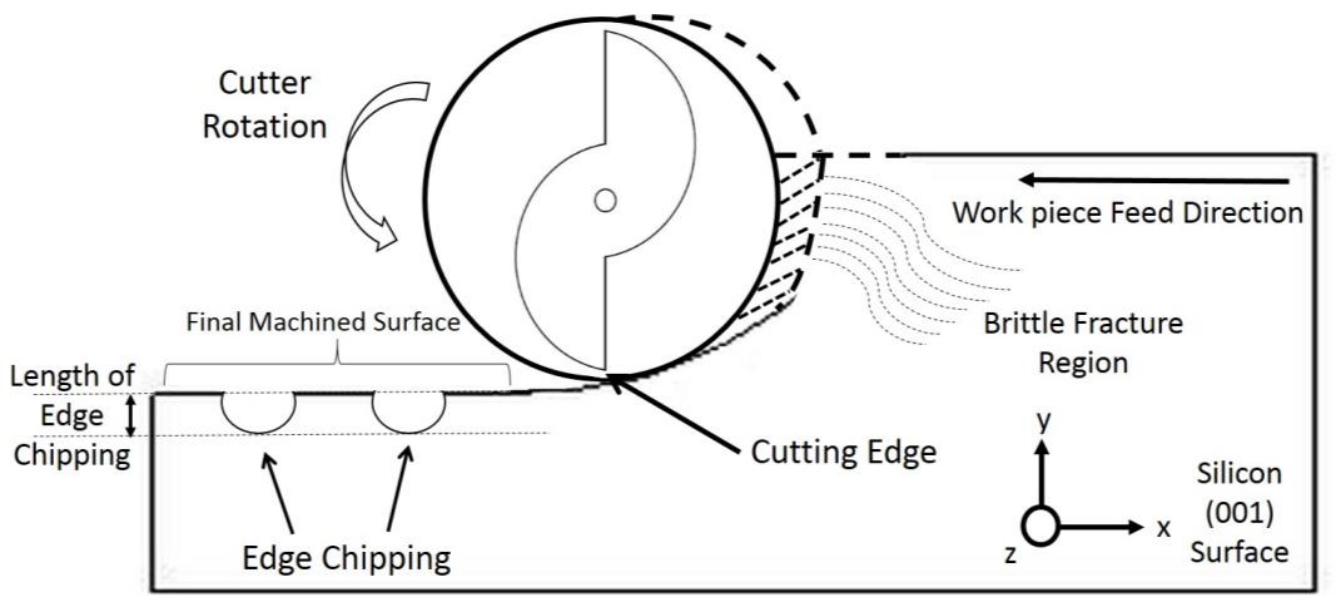

Figure 7: Schematic of micro-machined surface with chipping usually formed on the top surface of silicon.

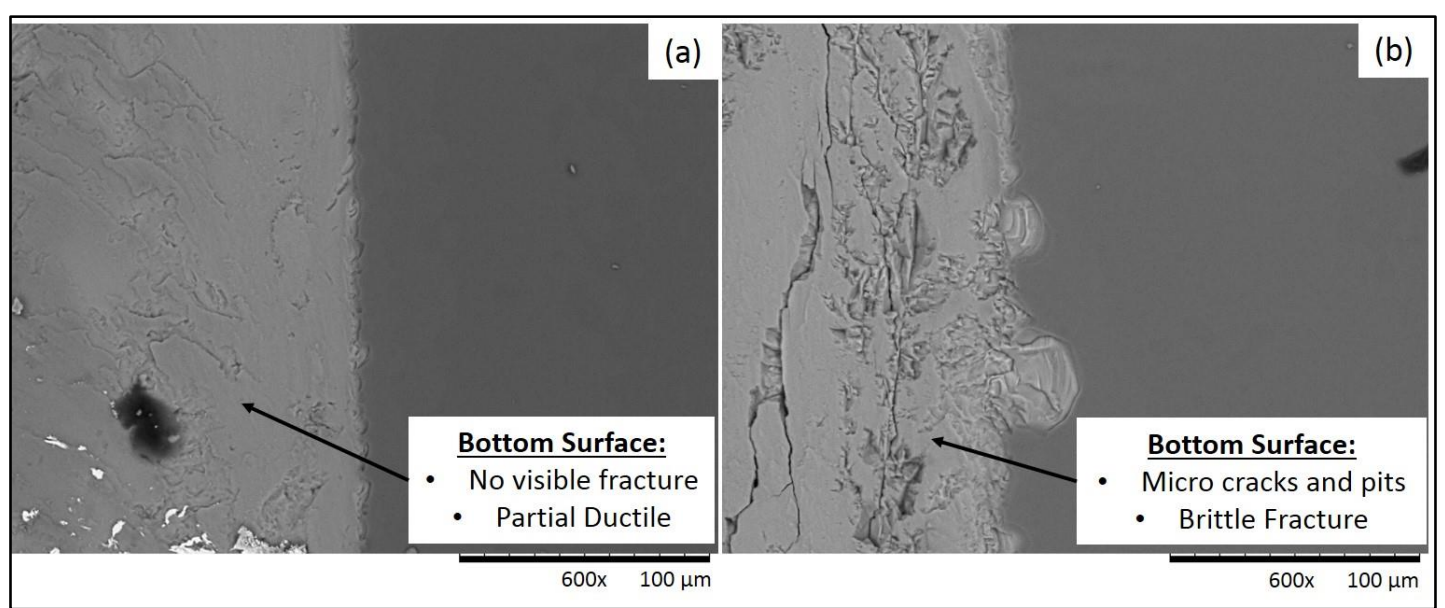

Figure 8: SEM imagery of (a) [010] and (b) [110] machined surfaces.

Table 5: Surface roughness and edge chipping measurement of [010] and [110] machined surfaces.

\begin{tabular}{ccc}
\hline Directions & Surface Roughness, $\mathbf{R}_{\mathbf{a}}(\boldsymbol{\mu m})$ & Length of Edge Chipping $(\boldsymbol{\mu m})$ \\
\hline$[010]$ & 0.397 & $\approx 4$ \\
{$[110]$} & 0.729 & $\approx 18$ \\
\hline
\end{tabular}

\subsection{Effect of Different Cutting Tools during Silicon Micro-Milling}

\subsubsection{Analysis on Surface Roughness and Edge Chipping}

Slot machining were performed along the [0ํㅣㄹ direction using three different end-mills namely diamond coated tungsten carbide, CVD diamond and single crystal diamond tools. Figure 9 and 10 shows the SEM images of post machining quality by the three cutting tools and final machined slots on the (001) silicon wafer by each respective tools. From the SEM 
images shown in Figure 9, single crystal diamond tool suffers the least amount of tool wear. In addition, both CVD and single crystal diamond tools achieved fracture free quality while diamond coated tungsten carbide tool suffers micro pits and cracks on the bottom machined surface as shown in Figure 10.

The bottom surface machined by CVD and single crystal diamond have no visible fracture because both tools having very sharp cutting edges due to the small cutting tool radius. This causes the impact force imposed on the sample surface during contact with the cutting tool to be small. Controversial results on the measured length of the edge chipping shown in Table 6 indicates that single crystal diamond tool generates the largest amount of edge chipping along the $[0 \overline{1} 0]$ cutting direction. Due to the limited understandings on tool wear in ultra-precision machining, no absolute explanation can be given to the mechanism of edge chipping behaviour when micro-milling was performed by either CVD or single crystal diamond tool. Diamond tool and diamond coated tool used in this experiment have different effective rake angle. The former has a nearly zero rake angle and the latter has a large negative rake angle.

Large negative rake angle is believed to create highly compressive hydrostatic pressure in the cutting zone, and the highly compressive hydrostatic pressure in turn can suppress the crack propagation. This might be a possible explanation to the large edge chip size generated during micro-milling with CVD or single crystal diamond tool. Although the method proposed to measure the length of edge chipping provides an estimation to quantify edge chipping, more precise method of quantification such as volume measurement of the generated chips should be investigated and applied in the future. 


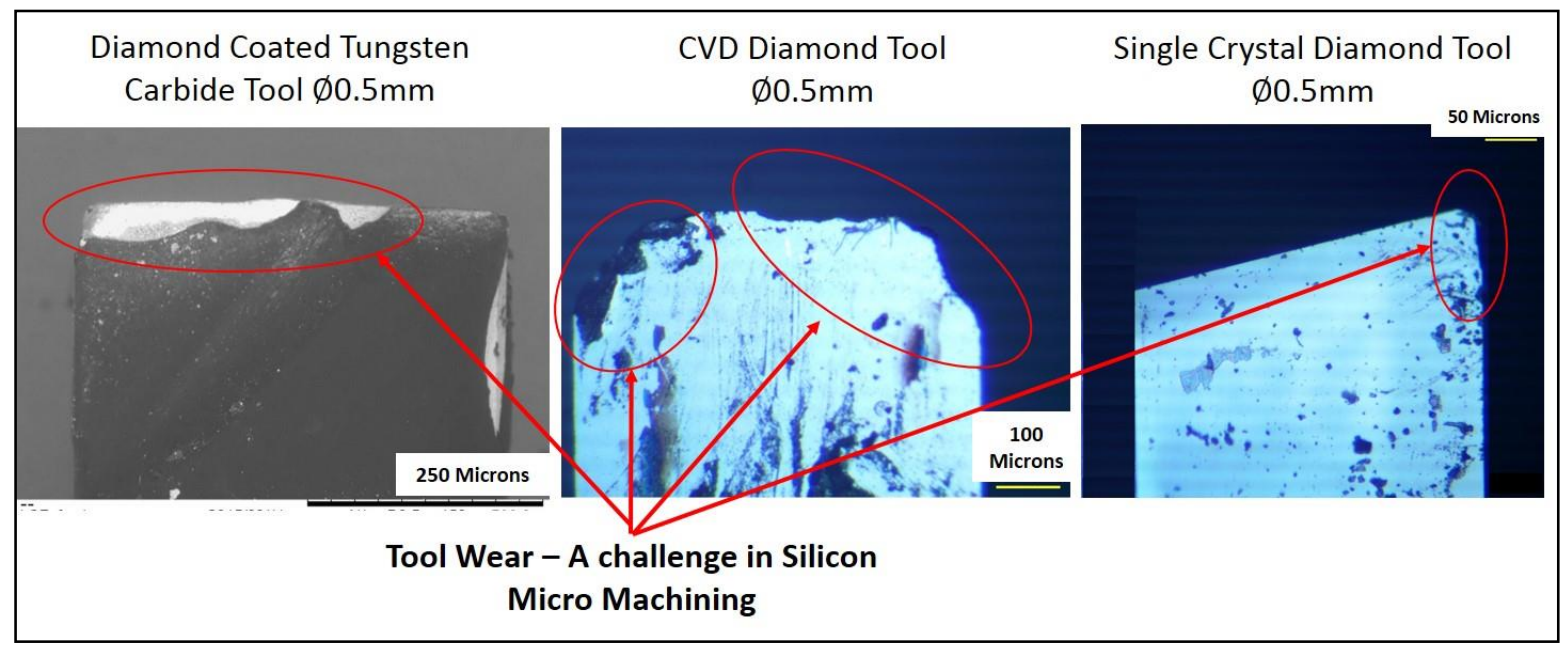

Figure 9: SEM images of tool wear on diamond coated, CVD and single crystal diamond tools.

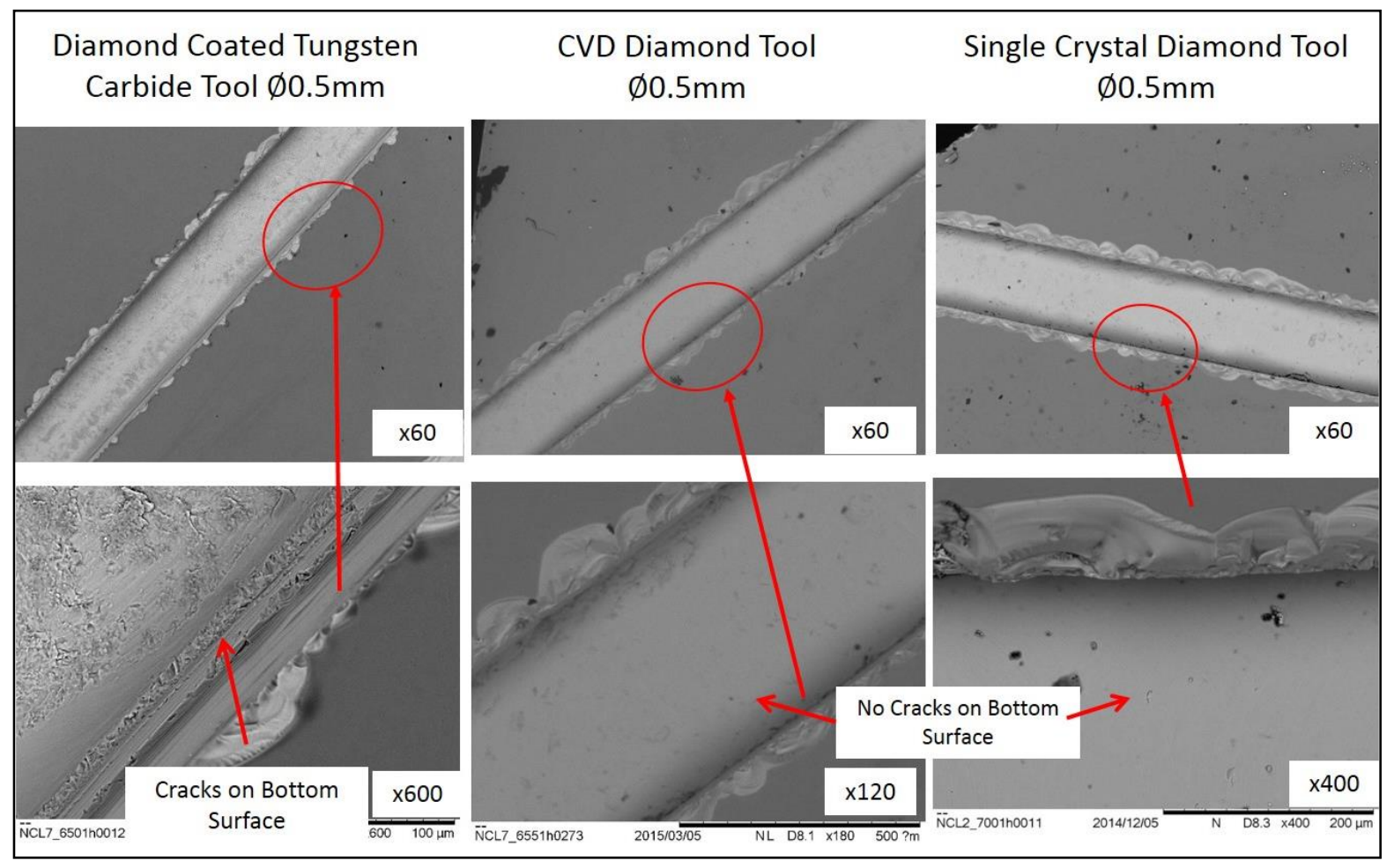

Figure 10: SEM images of machined slot on (001) Silicon Wafer by diamond coated, CVD and single crystal diamond tools at $\approx 150 \mu \mathrm{m}$ deep.

Table 6: Average and RMS Edge Chipping Length.

\begin{tabular}{cccc}
\hline & $\begin{array}{c}\text { Single Crystal } \\
\text { Diamond Tool }\end{array}$ & CVD Diamond Tool & $\begin{array}{c}\text { Diamond Coated } \\
\text { Tungsten Carbide } \\
\text { Tool }\end{array}$ \\
\cline { 2 - 4 } Avg. Edge Chip Length $(\mu \mathrm{m})$ & 66.47 & 55.36 & 16.24 \\
RMS Edge Chip Length $(\mu \mathrm{m})$ & 67.26 & 56.81 & 18.32 \\
\hline
\end{tabular}




\section{CONCLUSIONS}

The effect of crystallographic orientation during micro-milling of silicon was investigated and assessed through its cutting performance in this study. Surface roughness and edge chipping measurement indicates that surface quality along $\langle 100\rangle$ were better than those of $<110\rangle$. Furthermore, cutting forces measured along $<110\rangle$ were lower due to lower fracture toughness and surface energies. This leads to easy dislocation of atoms along <110> directions. Results from the comparative studies of different end-mills shows that diamond coated tool generates the least edge chipping, while single crystal diamond and CVD tool both generates fracture free bottom surface. Tremendous tool wear on diamond coated and CVD tools remains a challenge after silicon micro-milling operations.

This research is in agreement with previous studies as a significant presence of crystallographic orientation effect affecting the quality of machined silicon by micro-milling. Furthermore, results from this research had demonstrated that by machining silicon along $<100>$ directions, partial fracture free machining quality were achieved. However, in conjunction with previous studies, it was recognized that fracture free machining quality for brittle materials cannot solely depend on mechanical micro-machining. Generation of edge chipping remains a challenge even if machining were conducted along <100> directions. Future perspectives to develop mitigating strategies for such challenge would include the introduction of protection techniques to the silicon to minimise edge chipping.

\section{ACKNOWLEDGMENTS}

The authors wish to thank EPSRC (EP/M020657/1) and Newcastle University SAgE Doctoral Training Award scheme for the support of this work. The authors are also grateful to Air Bearings Ltd for providing the high speed air bearing spindles which were used in the experiments. 


\section{REFERENCES}

1. Liu X, DeVor RE, Kapoor SG and Ehmann KF. The Mechanics of Machining at the Microscale: Assessment of the Current State of the Science. Journal of Manufacturing Science and Engineering. 2005; 126: 666-78.

2. Madou MJ. Fundamentals of Microfabrication: The Science of Miniaturization, Second Edition. Taylor \& Francis, 2002.

3. Blackley WS and Scattergood RO. Ductile-regime machining model for diamond turning of brittle materials. Precision Engineering. 1991; 13: 95-103.

4. Leung TP, Lee WB and Lu XM. Diamond turning of silicon substrates in ductile-regime. Journal of Materials Processing Technology. 1998; 73: 42-8.

5. Yan J, Syoji K, Kuriyagawa T and Suzuki H. Ductile regime turning at large tool feed. Journal of Materials Processing Technology. 2002; 121: 363-72.

6. Ko TJ, Rusnaldy, Kim JG and Kim HS. Feasibility study of ductile regime machining of silicon in micro-end-milling. Proceedings of the First International Conference on Manufacturing, Machine Design and Tribology (ICMDT), Seoul, Korea, June 23-24, 2005, paper no. FCT 203.

7. Huo D, Chao L, Choong ZJ, Pancholi K, and Degenaar P. Surface and subsurface characterisation in micro-milling of monocrystalline silicon, International Journal of Advanced Manufacturing Technology, DOI: 10.1007/s00170-015-7308-7 (published ahead of print)

8. Maluf $\mathrm{N}$ and Williams K. An Introduction to Microelectromechanical Systems Engineering. Artech House, 2004.

9. Young W, Budynas R and Sadegh A. Roark's Formulas for Stress and Strain, 8th Edition. McGraw-Hill Education, 2011.

10. Griffith AA. The Phenomena of Rupture and Flow in Solids. 1921, p.163-98.

11. Jaccodine RJ. Surface Energy of Germanium and Silicon. Journal of The Electrochemical Society. 1963; 110: 524-7.

12. Chen CP and Leipold MH. Fracture Toughness of Silicon. American Ceramic Society Bulletin. 1980; 59: 469-72.

13. Hayashi K, Tsujimoto S, Okamoto Y and Nishikawa T. Fracture Toughness of Single Crystal Silicon. Journal of the Society of Materials Science, Japan. 1991; 40: 405-10.

14. Tanaka M, Higashida K, Nakashima H, Takagi H and Fujiwara M. Orientation dependence of fracture toughness measured by indentation methods and its relation to surface energy in single crystal silicon. Int J Fract. 2006; 139: 383-94.

15. Shibata T, Fujii S, Makino E and Ikeda M. Ductile-regime turning mechanism of singlecrystal silicon. Precision Engineering. 1996; 18: 129-37.

16. Hung NP and Fu YQ. Effect of Crystalline Orientation in the Ductile-Regime Machining of Silicon. Int J Adv Manuf Technol. 2000; 16: 871-6.

17. Cheung CF. Influence of cutting friction on anisotropy of surface properties in ultraprecision machining of brittle single crystals. Scripta Materialia. 2003; 48: 1213-8.

18. O'Connor BP, Marsh ER and Couey JA. On the effect of crystallographic orientation on ductile material removal in silicon. Precision Engineering. 2005; 29: 124-32.

19. Jasinevicius RG, Duduch JG, Montanari L and Pizani PS. Dependence of brittle-toductile transition on crystallographic direction in diamond turning of single-crystal silicon. Proceedings of the Institution of Mechanical Engineers, Part B: Journal of Engineering Manufacture. 2011. 
20. Rusnaldy, Ko TJ and Kim HS. A comparative machining study of TiCN, TiAlN and diamond coated tools in micro end milling of silicon wafer. LEM 2005 - 3rd International Conference on Leading Edge Manufacturing in 21st Century. 2005, p. 1257-61.

21. Huo D and Cheng K. Experimental investigation on micromilling of oxygen-free, highconductivity copper using tungsten carbide, chemistry vapour deposition, and singlecrystal diamond micro tools. Proceedings of the Institution of Mechanical Engineers, Part B: Journal of Engineering Manufacture. 2010; 224: 995-1003.

22. Altintas Y. Manufacturing Automation: Metal Cutting Mechanics, Machine Tool Vibrations, and CNC Design. Cambridge University Press, 2012. 